\title{
HUBUNGAN KEYAKINAN KELUARGA TERHADAP PERILAKU PERAWATAN KAKI DIABETES MELLITUS BERBASIS SELF EFFICACY DI PUSKESMAS WONOKROMO dan KEBONSARI KOTA SURABAYA
}

\section{Relationship of Family Belief on Care Behavior of Diabetes Mellitus Based on Efficacy Self in Puskesmas Wonokromo and Kebonsari City of Surabaya}

\author{
Nuh Huda, Dedi Irawandi, Sherley Ajeng
}

STIKES Hang Tuah Surabaya

\section{Riwayat artikel}

Diajukan: 11 Juli 2019

Diterima: 28 Maret 2020

\section{Penulis Korespondensi:}

- Dedi Irawandi

- STIKES Hang Tuah Surabaya

- dediirawandi911@gm ail.com

\section{Kata Kunci:}

Keyakinan, Perilaku perawatan kaki, Keluarga, Diabetes mellitus

\section{Abstrak}

Pendahuluan: Self Efficacy merupakan suatu keyakinan orang atau individu tersebut akan kemampuan mereka. Tujuan memperoleh hasil yang lebih dalam satu peristiwa yang mempengaruhi kehidupan mereka. Tujuan penelitian ini menganalisis hubungan keyakinan keluarga dengan perilaku perawatan kaki diabetes mellitus berbasis self efficacy.

Metode: Desain penelitian observasional analisis dengan pendekatancross sectional. Populasi semua keluarga yang memiliki penderita diabetes mellitus di Puskesmas Wonokromo dan Kebonsari Kota Surabaya. Teknik sampel menggunakan cluster sampling sebanyak 126 responden keluarga penderita diabetes. Instrument menggunakan wawacara terstruktur, kuesioner FCCS, dan kuesioner FCBS. Data dianalisa dengan uji korelasi spearman.

Hasil penelitian bahwa semakin tinggi keyakinan keluarga semakin rendah resiko perilaku merusak. Uji korelasi spearman menunjukkan bahwa adanya hubungan keyakinan keluarga dengan perilaku perawatan kaki diabetes mellitus $\rho=0,00(\rho<\alpha=$ $0,05)$.

Diskusi:Implikasi penelitian ini adalah keyakinan keluarga berhubungan dengan perilaku perawatan kaki diabetes mellitus, sehingga Puskesmas dapat memberikan sosialisasi sesuai dengan teori kepada keluarga yang memiliki penderita diabetes mellitus.

\section{Abstract}

Introduction: Self efficacy is a belief of people or individuals about their abilities. The purpose of getting more result in an event that affects their lives. The purpose of this study was to analyze the relationship between family belief and behavior treatment of diabetic mellitus based on self efficacy.

Observational study design analyst with cross sectional approach. The population of all families who have diabetic mellitus at the Wonokromo and Kebonsari Surabaya centers. The sample technique uses a cluster sampling of 126 responders in the family of diabetic. The instrument uses structured interviews, FCCS questionnaires, and FCBS questionnaires. Data was analyzed by spearman correlation test.

The results of the study that the higher the family's confidence the lower the risk of behavior. Spearman correlation the test showed that there was a correlation between family beliefs and diabetic mellitus foot care behavior $\rho=0,00(\rho<\alpha=$ $0,05)$.

The implication of this research is that family beliefs are related to diabetic mellitus foot care behavior, so the center can provide information in accordance with the theory to families who have diabetic mellitus sufferers. 


\section{Pendahuluan}

Diabetes mellitus merupakan penyakit metabolik gangguaan insulin yang ditandai dengan tingginya kadar gula dalam darah (Rahmawati, 2016). Penderita diabetes memiliki resiko tinggi terjadinya luka atau ulkus karena salah satu yang dirasakan penderita diabetes yaitu keterbatasan rentang gerak sehingga menimbulkan resiko terjadi ulkus lebih tinggi (Kale and Akoit, 2015).

Pada penelitian (Sihombing, 2012) responden dalam penelitiannya sudah melakukan perawatan kaki dengan baik. Penelitian lain yang dilakukan oleh (Kamaru Zaman NH, Mohd Shah NS, 2018) menunjukkan bahwa, praktik perawatan kaki yang buruk disebabkan kurangnya pengetahuan tentang perawatan kaki diabetes yang benar. Sementara itu hasil penelitian dari (Windani et al., 2016) bahwa perawatan kaki oleh keluarga terhadap pasien diabetes rendah, dikarenakan kurangnya keyakinan keluarga dalam merawat kaki pasien diabetes.

Terdapat berbagai cara untuk mencegah terjadinya ulkus pada penderita diabetes. Perawatan kaki yang baik dapat mencegah terjadinya komplikasi kaki diabetes dini dan perawatan kaki yang dimaksud yaitu memeriksa kaki setiap hari apakah bengkak dan ada perubahan warna, memeriksa alas kaki, mencuci kaki setiap hari menggunakan sabun dan air hangat, mengeringkan kaki dengan hati-hati, dan menggunting kuku secara rutin (Sihombing, 2012).

Sementara itu hasil penelitian dari (Kamaru Zaman NH, Mohd Shah NS, 2018) menjelaskan bahwa dengan memberikan pendidikan kesehatan tentang cara yang benar perawatan kaki diyakini akan mencegah terjadinya ulkus diabetik. Hal tersebut sejalan dengan penelitian yang dilakukan oleh (Kale and Akoit, 2015) pentingnya pemberian edukasi kesehatan tentang perawatan kaki untuk mencegah ulkus serta melakukan deteksi dini risiko luka kaki diabetik dengan menggunakan diabetic screen foot untuk menentukan resiko terjadinya luka kaki diabetik bagi penderita diabetes serta dari hasil study pendahuluan menunjukkan hasil bahwa 7 responden memiliki self efficacy perilaku perawatan kaki yang rendah. Berdasarkan uraian diatas, maka peneliti ingin meneliti tentang hubungan keyakinan keluarga terhadap perilaku perawatan kaki diabetes mellitus berbasis self efficacy di Puskesmas Wonokromo dan Kebonsari Kota Surabaya.

\section{METODE}

Penelitian ini merupakan jenis penelitian kuantitaif dengan desain penilitian menggunakan observasional analisis dengan pendekatan cross sectional untuk menganalisa hubungan keyakinan keluarga terhadap perilaku perawatan kaki diabetes mellitus berbasis self efficacy di Puskesmas Wonokromo dan Kebonsari Kota Surabaya. Jenis penelitian ini menekankan waktu pengukuran data variabel independen dan variabel dependen hanya satu kali dan satu saat (Nursalam, 2013).

\section{HASIL DAN PEMBAHASAN \\ HASIL}

Data Umum Penelitian

Tabel 1.1 Karakteristik Responden Berdasarkan Usia di Puskesmas Wonokromo dan Kebonsari Pada Tanggal 20 Mei 2019-31 Mei 2019 ( $N=126)$

\begin{tabular}{ccc}
\hline Usia & Frekuensi (f) & $\begin{array}{c}\text { Prosentase } \\
(\mathbf{\%})\end{array}$ \\
\hline $25-34$ & 1 & $8 \%$ \\
$35-44$ & 11 & $8,7 \%$ \\
$>45$ & 114 & $90,5 \%$ \\
\hline Total & $\mathbf{1 2 6}$ & $\mathbf{1 0 0 \%}$ \\
\hline
\end{tabular}

Berdasarkan tabel diatas menunjukkan bahwa dari 126 responden didapatkan sebagian besar responden berusia $>45$ tahun sebanyak 114 orang $(90,5 \%)$, berusia $35-44$ tahun sebanyak 11 orang $(8,7 \%)$ dan berusia 25-34 tahun sebanyak 1 orang $(8 \%)$.

Tabel 1.2 Karakteristik Responden Berdasarkan Jenis Kelamin di Puskesmas Wonokromo dan Kebonsari Pada Tanggal 20 Mei 2019-31 Mei 2019 ( $N=126)$

\begin{tabular}{ccc}
\hline Jenis & $\begin{array}{c}\text { Frekuensi } \\
\text { Kelamin }\end{array}$ & $\begin{array}{c}\text { Prosentase } \\
(\mathbf{\%})\end{array}$ \\
\hline Laki-laki & 31 & $24,6 \%$ \\
Perempuan & 95 & $75,4 \%$ \\
\hline Total & $\mathbf{1 2 6}$ & $\mathbf{1 0 0 \%}$ \\
\hline
\end{tabular}


Berdasarkan tabel diatas menunjukkan bahwa dari 126 responden didapatkan sebagian besar yang berjenis kelamin perempan sebanyak 95 orang $(75,4 \%)$, dan berjenis kelamin laki-laki sebanyak 31 orang $(24,6 \%)$.

Tabel 1.3: Karakteristik Responden Berdasarkan Tingkat Pendidikan di Puskesmas Wonokromo dan Kebonsari Pada Tanggal 20 Mei 2019-31 Mei 2019 ( $N=126)$

\begin{tabular}{ccc}
\hline $\begin{array}{c}\text { Tingkat } \\
\text { Pendidikan }\end{array}$ & $\begin{array}{c}\text { Frekuensi } \\
(\mathbf{f})\end{array}$ & $\begin{array}{c}\text { Prosentase } \\
(\boldsymbol{\%})\end{array}$ \\
\hline Tidak Sekolah & 12 & $9,5 \%$ \\
SD & 31 & $24,6 \%$ \\
SMP & 30 & $23,8 \%$ \\
SMA & 47 & $37,3 \%$ \\
Perguruan & 6 & $4,8 \%$ \\
Tinggi & & $\mathbf{1 0 0 \%}$ \\
\hline Total & $\mathbf{1 2 6}$ &
\end{tabular}

Berdasarkan tabel diatas menunjukkan bahwa dari 126 responden didapatkan sebagian besar berpendidikan SMA sebanyak 47 orang (37,3\%), berpendidikan SD sebanyak 31 orang $(24,6 \%)$, berpendidikan SMP sebanyak 30 orang $(23,8 \%)$, tidak sekolah sebanyak 12 orang $(9,5 \%)$, dan berpendidikan perguruan tinggi sebanyak 6 orang $(4,8 \%)$.

Tabel 1.4 Karakteristik Responden Berdasarkan Pengalaman Melakukan Perawatan Kaki Diabetes Mellitus di Puskesmas Wonokromo dan Kebonsari Pada Tanggal 20 Mei 2019-31 Mei 2019 (N = 126)

\begin{tabular}{lcc}
\hline Pengalaman & $\begin{array}{c}\text { Frekuensi } \\
(\mathbf{f})\end{array}$ & $\begin{array}{c}\text { Prosentase } \\
(\mathbf{\%})\end{array}$ \\
\hline Pernah & 126 & $100 \%$ \\
Tidak Pernah & 0 & $0 \%$ \\
\hline Total & $\mathbf{1 2 6}$ & $\mathbf{1 0 0 \%}$
\end{tabular}

Berdasarkan tabel diatas menunjukkan bahwa dari 126 responden didapatkan hasil sebanyak 126 orang (100\%) mempunyai pengalaman dalam melakukan perawatan kaki diabetes mellitus.

\section{Data Khusus Penelitian}

Tabel 1.5 Karakteristik Responden Berdasarkan Keyakinan di Puskesmas Wonokromo dan Kebonsari Pada Tanggal 20 Mei 2019 - 31 Mei 2019 ( $N=126)$

\begin{tabular}{ccc}
\hline Keyakinan & $\begin{array}{c}\text { Frekuensi } \\
(\mathbf{f})\end{array}$ & $\begin{array}{c}\text { Prosentase } \\
(\boldsymbol{\%})\end{array}$ \\
\hline Self Efficacy & 4 & $3,2 \%$ \\
Rendah & &
\end{tabular}

\begin{tabular}{ccc}
$\begin{array}{c}\text { Self Efficacy } \\
\text { Tinggi }\end{array}$ & 122 & $96,8 \%$ \\
\hline Total & $\mathbf{1 2 6}$ & $\mathbf{1 0 0 \%}$ \\
\hline
\end{tabular}

Berdasarkan tabel diatas menunjukkan bahwa dari 126 responden didapatkan hasil sebanyak 122 orang $(96,8 \%)$ mempunyai keyakinan tinggi dan sebanyak 4 orang $(3,2 \%)$ memiliki keyakinan rendah.

Tabel 1.6 Karakteristik Responden Berdasarkan Resiko Perilaku Merusak Kesehatan di Puskesmas Wonokromo dan Kebonsari Pada Tanggal 20 Mei 2019 - 31 Mei $2019(N=126)$

\begin{tabular}{ccc}
\hline $\begin{array}{c}\text { Resiko } \\
\text { Perilaku } \\
\text { Merusak }\end{array}$ & $\begin{array}{c}\text { Frekuensi } \\
(\mathbf{f})\end{array}$ & $\begin{array}{c}\text { Prosentase } \\
(\mathbf{\%})\end{array}$ \\
\hline Resiko & 122 & $96,8 \%$ \\
Perilaku & & \\
Merusak & & \\
Kesehatan & & \\
Rendah & & \\
Resiko & 4 & $3,2 \%$ \\
Perilaku & & \\
Merusak & & \\
Kesehatan & & \\
Tinggi & & \\
\hline Total & $\mathbf{1 2 6}$ & $\mathbf{1 0 0 \%}$ \\
\hline Beral
\end{tabular}

Berdasarkan diatas menunjukkan bahwa dari 126 responden didapatkan hasil sebanyak 122 orang $(96,8 \%)$ mempunyai resiko perilaku merusak kesehatan rendah dan sebanyak 4 orang $(3,2 \%)$ mempunyai resiko perilaku merusak kesehatan tinggi.

\section{PEMBAHASAN}

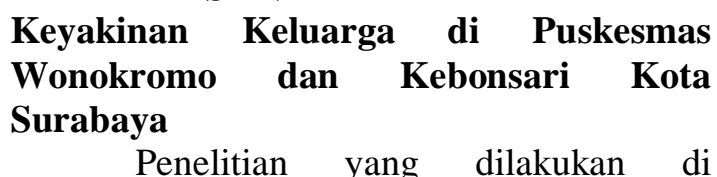
Puskesmas Wonokromo dan Kebonsari kota Surabaya sebagian besar dari total responden 126 orang memiliki keyakinan tinggi sebanyak 122 orang $(96,8 \%)$ dan memiliki keyakinan rendah sebanyak 4 orang $(3,2 \%)$. Hasil wawancara yang dilakukan peneliti kepada responden didapatkan hasil jawaban sama dengan yang ditulis didalam lembar kuesoner yaitu responden mengatakan apabila responden memiliki keyakinan tinggi maka responden akan bisa melakukan perawatan kaki diabetes mellitus secara benar. Keyakinan diri menentukan bagaimana orang tersebut merasa, berpikir, memotivasi diri 
dalam berperilaku menurut (Ramachaudran, 1998).

Peneliti berasumsi bahwa responden yang memiliki usia diatas 40 tahun memiliki pengalaman selama hidup yang sudah dilaluinya serta dengan menghadapi setiap rintangan dan tantangan dalam hidupnya responden lebih memiliki kepercayaan diri yang tinggi, sehingga self efficacy responden di puskesmas Wonokromo dan Kebonsari kota Surabaya sebagian besar memiliki keyakinan yang tinggi.

Perilaku Perawatan Kaki Diabetes Mellitus Berbasis Self Efficacy di Puskesmas Wonokromo dan Kebonsari Kota Surabaya

Penelitian yang dilakukan di Puskesmas Wonokromo dan Kebonsari kota Surabaya sebagian besar dari total responden 126 orang memiliki resiko perilaku merusak rendah sebanyak 122 orang $(96,8 \%)$ dan resiko perilaku merusak tinggi sebanyak 4 orang $(3,2 \%)$. Jenis perawatan kaki yang benar meliputi perawatan kaki secara rutin, mencuci kaki dengan sabun, memakai alas kaki, memeriksa alas kaki sebelum digunakan, memberikan lotion, memotong kuku (Diana, 2013).

Perilaku yang didasari oleh pengetahuan, kesadaran dan sikap positif (Kurniawan, 2011), maka peneliti berasumsi bahwa perilaku tersebut akan bersifat langgeng (long lasting) dan sebaliknya jika perilaku itu sendiri tidak didasari oleh pengetahuan dan kesadaran yang tinggi maka akan tidak berlangsung lama, sehingga hasil penelitian dari responden di Puskesmas Wonokromo dan Kebonsari kota Surabaya memiliki resiko perilaku merusak rendah.

Hubungan Keyakinan Keluarga Dengan Perilaku Perawatan Kaki Diabetes Mellitus Berbasis Self Efficacy Di Puskesmas Wonokromo dan Kebonsari Kota Surabaya

Berdasarkan hasil uji statistic pada penderita diabetes mellitus pasien Puskesmas Kebonsari dan Wonokromo Kota Surabaya terdapat hubungan keyakinan keluargaterhadap perilaku perawatan kaki berbasis self efficacy. Nilai korelasi pada hasil analisis SPSS ialah $-1,000$ yang berarti berkorelasi negative.Nilai significancy pada penelitian ini yaitu $\rho=0,000(\rho<\alpha 0,05)$ yang berarti memiliki hubungan negatif signifikan, sehingga semakin tinggi keyakinan keluarga maka resiko perilaku merusak semakin rendah dan sebaliknya jika keyakinan keluarga semakin rendah maka resiko perilaku merusak akan tinggi. Hasil tersebut dapat diketahui dari $96,8 \%$ dari keluarga penderita diabetes militus pasien Puskesmas Wonokromo dan Kebonsari merasa memiliki keyakinan dalam merawat kaki keluarga yang mengidap diabetes militus.

Menurut asumsi peneliti, individu mampu melakukan suatu hal (perawatan kaki) tehadap keluarganya jika memiliki keyakinan yang baik dalam melakukan perawatan kaki tersebut pula dan semakin tinggi pula kualitas hidup keluarga yang mengidap diabetes militus. Hal ini sejalan dengan hasil penelitian yang dilakukan oleh (Rahmawati, 2016) yang menyebutkan bahwa semakin tinggi keyakinan atau self efficacy yang dimiliki pasien diabetes maka semakin tinggi kualitas hidup pasien DM tipe 2 .

\section{KESIMPULAN}

Hasil penelitian dan pengujian dapat disimpulkan, sebagai berikut :

1. Terdapat hubungan keyakinan keluarga dengan perilaku perawatan kaki Diabetes Militus berbasis Self Efficacy di Puskesmas Wonokromo Kota Surabaya.

2. Terdapat hubungan keyakinan keluarga dengan perilaku perawatan kaki Diabetes Militus berbasis Self Efficacy di Puskesmas Kebonsari Kota Surabaya.

\section{DAFTAR PUSTAKA}

Diana, N. (2013) Pengetahuan dan praktik perawatan kaki pada klien diabetes melitus tipe 2 di kalimantan selatan. Universitas Indonesia.

Kale, E. D. and Akoit, E. E. (2015) 'Analisis risiko luka kaki diabetik pada penderita $\mathrm{dm}$ di poliklinik $\mathrm{dm}$ dan penyakit dalam', Jurnal Info Kesehatan. vol 14. 2 (Desember).

Kurniawan, V. E. (2011) Pengaruh Konseling Terhadap Pengetahuan, Sikap, Perilaku Penderita Diabetes Mellitus (DM) Tentang Perawatan Kaki Di Wilayah Kerja Puskesmas Kabuh. Universitas Sebelas Maret Surakarta.

Nursalam (2013) Metodologi Penelitian Ilmu Keperawatan Pendekatan Praktis. Edisi 3. Jakarta: Salemba Medika.

Ramachaudran (1998) 'Self-Efficacy', Ensiklopedia Manusia. Available at: 
https://www.uky.edu.

Rahmawati, N. (2016) Hubungan Efikasi Diri

Terhadap Kulitas Hidup Pasien Diabetes Mellitus Tipe 2 Di RS PKU Muhammadiyah Yogyakarta. Universitas Muhammasdiyah Yogyakarta.

Sihombing, D. (2012) 'Gambaran Perawatan Kaki Dan Sensasi Sensorik Kaki Pada Paiesn Diabetes Mellitus Tipe 2 Di Poliklinik DM RSUD', 14, pp. 114.

Availableat:http://www.journal.unpad. ac.id.

Windani, C. et al. (2016) 'Pengaruh Program
Edukasi Perawatan Kaki Berbasis

Keluarga terhadap Perilaku

Perawatan Kaki pada Pasien Diabetes

Melitus Tipe 2 Effectiveness of Family

Based Foot Care Education Program towards Foot Care Behavior of Type 2 Diabetes Mellitus Patients', Jurnal Keperawatan, 4.

Kamaru Zaman NH, Mohd Shah NS, (2018) Knowledge And Practice Of Foot Care Among Diabetic Elderly In Ukm Medical Centre ( Ukmmc )', The Malaysian Journal of Nursing, 9 (January), pp. 6- 